\title{
Pierre BRANDA, Napoléon et ses hommes
}

Paris, Fayard, 2011, 576 p., ISBN 978-2-73535-1736-3, 29,50€.

\section{Alan Forrest}

\section{Q OpenEdition}

\section{$\checkmark$ Journals}

\section{Édition électronique}

URL : https://journals.openedition.org/ahrf/12915

DOI : 10.4000/ahrf.12915

ISSN : 1952-403X

Éditeur :

Armand Colin, Société des études robespierristes

\section{Édition imprimée}

Date de publication : 1 septembre 2013

Pagination : 228-231

ISBN : 9782200928261

ISSN : 0003-4436

Référence électronique

Alan Forrest, "Pierre BRANDA, Napoléon et ses hommes ", Annales historiques de la Révolution française [En ligne], 373 | juillet-septembre 2013, mis en ligne le 03 octobre 2013, consulté le 01 juillet 2021. URL : http://journals.openedition.org/ahrf/12915; DOI : https://doi.org/10.4000/ahrf.12915

Ce document a été généré automatiquement le 1 juillet 2021.

Tous droits réservés 


\title{
Pierre BRANDA, Napoléon et ses hommes
}

\author{
Paris, Fayard, 2011, 576 p., ISBN 978-2-73535-1736-3, 29,50€.
}

\section{Alan Forrest}

\section{RÉFÉRENCE}

Pierre BRANDA, Napoléon et ses hommes. Paris, Fayard, 2011, 576 p., ISBN

978-2-73535-1736-3, 29,50€.

1 Toujours conscient de l'importance de son image comme outil du pouvoir, Napoléon cherchait à se présenter à ses contemporains et devant l'Histoire sous deux visages contrastés, les deux inventés et soigneusement maquillés pour créer l'impression requise. Pour les uns - et surtout pour ses anciens compagnons d'armes - il restait l'héritier de la Révolution, l'homme des Lumières, celui qui par ses talents seuls s'était tracé un chemin fulgurant dans le monde méritocratique des années 1790 pour prendre sous le Consulat et l'Empire les rênes du pouvoir politique. Pour les autres - parmi eux les rois et les reines d'Europe qu'il voulait impressionner et avec lesquels il voulait traiter d'égal à égal en diplomatie comme en guerre - il devait apparaitre comme un des leurs, un homme défini par le pouvoir et respirant la majesté royale. Cette image pouvait changer, d'ailleurs, soudainement, en fonction du public et des contingences politiques : en 1810 lors de son mariage avec Marie-Louise, c'est un homme du pouvoir doté de toutes les richesses d'un grand empire, suivant à la lettre le déroulé du mariage de Louis XVI et de Marie-Antoinette, tandis qu'en 1815, pendant les Cent-Jours, il revient à son image modeste d'antan, au personnage du " petit caporal », proche de ses hommes dans leurs combats et leurs souffrances. Selon les circonstances, on le voit rattrapé par son passé républicain ou s'adonner aux plaisirs matériels de la monarchie, tiraillé, comme Janus, dans deux directions et vers deux mondes et deux idéaux, qui sont finalement contradictoires. Mais lequel est le vrai Napoléon ? C'est en examinant de près, comme le fait ici Pierre Branda, le fonctionnement de sa cour et le quotidien de la Maison de l'empereur, qu'on peut trancher entre ces deux figures pour offrir une vision nouvelle des caractéristiques du pouvoir impérial. 
2 Pierre Branda continue ici un travail qu'il avait commencé en 2007 dans un ouvrage sur Le Prix de la Gloire. Napoléon et l'argent, publié également par Fayard, qui avait la témérité de fouiller dans les caisses impériales pour dévoiler la fortune considérable qu'accumula l'empereur pendant ses années de campagnes militaires. Derrière le noble discours sur la gloire et l'honneur, il s'intéressait de très près à l'argent et à la richesse, et les taxes et les contributions imposées sur les pays conquis et annexés à l'Empire ont largement contribué à cette fortune. Dans sa recherche de ressources pour ses armées et pour la nation - son Musée Napoléon serait largement alimenté par les trophées de guerre arrachés à l'Italie, en Allemagne, en Égypte et ailleurs - Napoléon n'oubliait jamais ses intérêts personnels ni ceux de sa famille. L'argent, semble-t-il, comptait autant pour lui que pour son empire.

Ce volume, intitulé Napoléon et ses hommes, examine de près - et avec un esprit parfois très critique - son mode de vie, le style de sa cour, les services personnels qu'il exigea une fois de retour à Paris et installé comme Premier Consul et ensuite comme empereur. Pierre Branda est le premier historien à entreprendre cette vaste recherche, examinant avec minutie les comptes de la maison impériale et les vastes coûts qu'elle entraînait, et les volumineuses correspondances qu'elle a produites depuis sa création jusqu'à sa fin dérisoire, décrite ici comme la «Cour miniature de l'île d'Elbe, celle ressuscitée des Cent-Jours et celle fantomatique de Sainte-Hélène ». Le goût pour le luxe commence tôt, et on voit Bonaparte, devant son armée en Italie, dîner somptueusement et avec un cérémonial conçu pour laisser chez les spectateurs une image saisissante de sa personne. Une fois à la tête de l'Empire, il n'a aucune raison de ne pas se laisser aller à son penchant. Même en exil, sur l'île d'Elbe, et plus tard à Sainte-Hélène, il continue à jouer l'empereur des Français, avec une cour diminuée, composée de ses quelques amis et alliés qui l'avaient suivi en exil, remplissant ainsi le rôle de ses rêves. La culture des apparences, semble-t-il, continue à l'inspirer tellement il en est devenu l'esclave.

4 L'étude de Pierre Branda éclaire le mode de vie de l'empereur, perçu comme un nouveau roi ayant besoin d'un personnel considérable pour gérer ses possessions et sa cour. Il s'agit des gens attachés à la Maison de l'empereur, institution créée à l'image de la Maison du Roi de Louis XVI, avec ses fonctions différentes, ses services généraux, ses services particuliers. Il est intéressant de voir, d'ailleurs, que les grands officiers et les grands dignitaires que lui attribue la constitution de l'an XII, répondent à Napoléon seul. Il se montre totalement incapable de déléguer le moindre détail. Comme sa correspondance le démontre, il s'immisce dans tout, et nul détail - sur le cérémonial de l'État, le menu des banquets impériaux, ou l'achat de chevaux pour les écuries impériales - n'est trop insignifiant pour retenir son attention. Il s'occupe de tout, donne des ordres à ses valets et domestiques, s'intéresse à leurs obligations comme à leur tenue. Pour ce qui est des grands officiers, il les choisit généralement parmi ses proches, des hommes de confiance qu'il connaît pour être dévoués à son service, les Caulaincourt, les Fesch, les Daru, les Talleyrand. Au cours des années, d'ailleurs, le nombre de gens qu'il employait dans sa Maison personnelle a augmenté considérablement: en 1813 la Maison de l'empereur et celle de l'Impératrice incorporaient presque 220 personnes - "une véritable petite armée de serviteurs » tandis qu'en 1788 Louis XVI et Marie-Antoinette avaient été critiqués pour leur vie dispendieuse à un moment où leur Maison n'en employait que 52 . 
5 Napoléon, voulant affirmer sa légitimité en tant que monarque, se trouvait contraint d'imiter, ici comme dans tant d'autres sphères de la vie publique, la monarchie de l'Ancien Régime, son style, sa consommation, son cérémonial. Et à quel point! En février 1800, dans les premiers mois du Consulat, celui qui serait Premier Consul avait déjà élu domicile dans les anciens appartements royaux du Palais des Tuileries, espace somptueux qu'il voulait transformer et remodeler à son goût. La France était toujours une République - et une bonne partie du programme politique de Napoléon serait profondément enraciné dans la pensée républicaine - mais dans son mode de vie et dans son appréciation du pouvoir ses desseins s'avèrent déjà monarchiques. Il avait un goût particulier pour l'étiquette et insistait sur son observation même quand il était en voyage. Il le fallait, disait-il, pour impressionner ses administrés et pour imposer une image puissante sur les monarchies de l'Europe.

6 Les chiffres que produit Pierre Branda pour soutenir son argument sont impressionnants, les coûts de la Maison de l'empereur également. Aux Tuileries, Napoléon jouit des services du grand maréchal pour organiser sa sécurité, et du grand écuyer pour organiser les écuries et acheter des chevaux (et il devient évident que Napoléon choisit les chevaux pour leur beauté autant que pour leur puissance et leur efficacité : en 1808 il alloue un budget de 240000 francs à l'achat de ces chevaux arabes qu'il avait tellement admirés en Égypte). Il voulait aussi que le monde le voie comme un homme cultivé, avec un grand appétit pour l'art et pour la lecture. Il employait donc des bibliothécaires dans ses palais - dans ses bibliothèques il avait une collection d'au moins 60000 livres - et il louait les services de musiciens, d'acteurs et d'artistes pour ajouter un air artistique à ses banquets et ses bals. Tout est fait pour laisser une impression de pouvoir et de bon goût, dans le cérémonial surtout, qui devait démontrer visiblement ce qu'était la puissance de l'empereur. Dans ce but, il se mit ensuite à reconstituer la cour de l'Ancien Régime, recréant une Maison des pages en 1805, ainsi que ces fonctions classiques de la monarchie, la grande aumônerie et la vénerie même si, comme l'explique l'auteur, Napoléon lui-même n'avait aucun intérêt pour la religion et aucun talent pour la chasse, mais c'étaient les activités monarchiques par excellence qui ajouteraient de l'éclat à son règne et à son empire. Il employait même des fauconniers pour son service de rapaces. Et comme les rois d'antan, il donnait aux pauvres, même si, d'après l'auteur, il s'agissait de dons modestes («la charité napoléonienne fut donc bien décevante »). En tout cas, le but de ces actes de charité est transparent. Tout était fait pour faire honneur à sa personne, tout devait refléter sa gloire. Et pour les grandes occasions - le Sacre surtout, mais aussi son mariage avec Marie-Louise et la naissance de son fils et héritier - aucune dépense n'est jugée excessive. Médailles, illuminations, cortèges, feux d'artifice : à l'Intendance revient la responsabilité d'amuser le peuple.

7 Dans une longue tradition monarchique également, Napoléon cherchait à laisser, dans Paris surtout, un mémorial architectural durable qui serait digne de l'empereur des Français. C'est dans ce but qu'il se mit à rénover ses palais et leurs parcs, des Tuileries à Malmaison, Fontainebleau ou Rambouillet. Il pensait même à rénover le Palais de Versailles, symbole ultime de la grandeur du Roi-soleil; et dans Paris il achetait et vendait des propriétés et autorisait des démolitions pour préparer et financer ses constructions. Encore une fois nous le trouvons interventionniste, obsédé par le détail, refusant de faire confiance aux architectes qu'il employait et avec qui il entretenait d'assez mauvaises relations. Mais un empereur qui passait une si grande partie de son 
temps en campagne, hors de France et loin de Paris, ne pouvait pas tout diriger : en conséquence, son " gros œuvre » de rénovation et d'embellissement est resté largement incomplet. Le parc immobilier de Paris n'a pas beaucoup changé pendant son règne en dépit de ses ambitions grandioses. Il faut donc conclure avec l'auteur que le résultat est assez modeste, et que "dans ce domaine il ne fut guère le grand bâtisseur que l'on aurait $\mathrm{pu}$ attendre : «sous son règne on s'agita plus sur le papier que l'on ne construisit ». 